\title{
Prevalence of Osteoarthritis and Health-Related Quality of Life in Stroke Patients: A Cross-Sectional Study Using Korean National Health and Nutrition Examination Survey VII
}

\author{
Kil-Yong Jeong \\ Ajou University Hospital \\ Hyun Jung Lee ( $\nabla$ sigano@hanmail.net ) \\ Jeju National University Hospital https://orcid.org/0000-0003-0202-587X
}

\author{
Research article \\ Keywords: Osteoarthritis, Stroke, Prevalence, Health-related quality of life, Cross-Sectional Studies \\ Posted Date: June 23rd, 2020 \\ DOI: https://doi.org/10.21203/rs.3.rs-37188/v1 \\ License: (c) (i) This work is licensed under a Creative Commons Attribution 4.0 International License. Read Full License
}




\section{Abstract}

Background: The purpose of this study was to analyze the risk factors affecting the prevalence of osteoarthritis and the health-related quality of life (HRQoL) of stroke patients from various angles, including demographic factors, socioeconomic factors, comorbidities, and lifestyle factors.

Methods: A total of 13,959 patients $\geq 40$ years of age (stroke group $n=416$, non-stroke group $n=13,535$ ) were identified from the 2016 -2018 Korean National Health and Nutrition Examination Survey for analysis. The European quality of life- 5 dimensions questionnaire was used to compare the differences in stroke patient's HRQoL according to the presence or absence of osteoarthritis. Multiple regression analysis was performed to determine the factors affecting the HRQoL of the stroke group.

Results: The prevalence of osteoarthritis was $21.72 \%$ in the stroke group and $12.49 \%$ in the non-stroke group. The prevalence of osteoarthritis in female patients who had strokes was $35.95 \%$ and was significantly higher than that of male patients who had strokes (10.23\%). The European quality of life-5 dimensions index indicating HRQoL was significantly lower in stroke group with osteoarthritis. Factors that significantly influenced the HRQoL in the stroke group were the presence of osteoarthritis, aerobic exercise, drinking status, types of health insurance, and educational levels.

Conclusions: This study confirmed that the HRQoL was significantly lower in stroke group with osteoarthritis. Findings were taken to suggest that the active management of osteoarthritis in stroke patients are important.

\section{Background}

Stroke is a disease that can cause physical and mental impairments and is often accompanied by a decline in quality of life due to these chronic sequelae [14]. According to an epidemiological report published by the Korean Stroke Society in 2018, 1 in 40 Korean adults have had a stroke, and 232 strokes occur per 100,000 people each year [5]. With the advancement of medical care, the mortality rate of patients with stroke has decreased over time [6], resulting in an increase in the number of patients living with the disease and its associated disorders.

Disability that results from stroke includes not only neurological disorders, but also deterioration of physical function [7, 8]. The incidence of musculoskeletal issues is commonly reported as $29-32 \%$ [9]. The decline of muscle strength and/or motor control function, in addition to muscle spasticity, can cause abnormalities of the limbs and an irregular gait. These resulting physical symptoms may also increase pain and limit activities of daily living [10].

In particular, osteoarthritis, caused by degenerative joint changes, is one of the diseases that typically accompanies stroke due to its increasing prevalence with age [11-13]. Osteoarthritis is characterized by chronic joint pain and functional limitations including gait instability [14]. It can worsen the function of patients suffering from stroke $[15,16]$, negatively impacting their health-related quality of life (HRQoL).

Quality of life reflects the course and prognosis of disease and is an important indicator of patients' function and their subjective satisfaction and happiness [17]. Subsequently, decline in HRQoL is associated with the occurrence of depression, decreased motivation, and social withdrawal. This can lead to the deterioration of other functions, activity, and mobility. Improving the HRQoL of patients with strokes not only improves their mental outlook but can lead to functional improvements and increased social participation.

An aging society is defined as a society with more than $7 \%$ of the elderly aged 65 years or older; an aged society, more than $14 \%$; and a super-aged society, more than $20 \%$. Therefore, Korea, currently an aging society, is expected to become a super-aged society in 2030 , with $24.9 \%$ of the population aged 65 years or older [18]. Life expectancy in 2030 is also estimated to reach the world's highest rate of 84 years of age for men and 91 years of age for women [19]. Thus, research related to stroke and osteoarthritis in Korea is expected to receive increased attention in the future.

Currently, research regarding the quality of life of patients with strokes and related comorbidities in Korea is very limited, and the number of studies is small. Therefore, the purpose of this study was to understand the prevalence of osteoarthritis and the factors affecting the HRQoL of patients $\geq 40$ years of age who have had strokes using data from the 7th Korean national health and nutrition examination survey (KNHANES).

\section{Materials And Methods Subjects}

This study was a secondary data analysis using raw data from the 7th KNHANES between 2016 and 2018 for patients $\geq 40$ years of age who had strokes. The KNHANES documents health behavior, prevalence of chronic disease, and dietary intake.

A total of 24,269 people responded to this survey. In this study, a 416 individuals $\geq 40$ years of age were selected as the stroke group comprised those diagnosed with stroke or were currently undergoing treatment for stroke. The non-stroke group included 13,535 individuals. The stroke group with osteoarthritis included those who were diagnosed with osteoarthritis or were being treated for this disease. In the stroke group, 103 individuals had osteoarthritis, and 313 individuals did not have osteoarthritis. In the non-stroke group, 1,999 individuals had osteoarthritis, and 11,032 individuals did not have osteoarthritis (Fig. 1). This study was approved by the Jeju National University Hospital Institutional Review Board (IRB No.2020-05-001).

\section{Research design and explanatory variables}

In this study, the prevalence of osteoarthritis was analyzed in the stroke group, and the European quality of life-5 dimension (EQ-5D) system, developed by the EuroQoL Group [20], was used to compare the differences in the HRQoL according to the presence or absence of osteoarthritis in the stroke group. The EQ-5D

Page 2/10 
consists of five dimensions related to HRQoL: mobility, self-care, daily activities, pain/discomfort, and anxiety/depression. Each dimension has a three-point scale consisting of 'no problem at all, somewhat of a problem, and severe problem'. A higher score is related to greater discomfort in each dimension. The EQ$5 \mathrm{D}$ tool results were then converted into one EQ-5D index according to the Korean EQ-5D measurement standards proposed by the Korea Centers for Disease Control and Prevention [21]. An EQ-5D index of 1 (when all five items were 1) defined a perfectly healthy condition. If there were mixed responses of 2 or 3 , the following weighted formula was used:

\section{EQ-5D}

$=1-(0.05+0.096 \times \mathrm{M} 2+0.418 \times \mathrm{M} 3+0.046 \times \mathrm{SC} 2+0.136 \times \mathrm{SC} 3+0.05$

$M=$ mobility, $A D=$ anxiety/depression, $P D=$ pain/discomfort, $S C$ = self-care, $U A$ = usual activities, and N3 indicates a response of ' 3 ' for all five items, which is indicative of the worst health condition.

A response of 2 for mobility is defined as M2 and a response of 3 for mobility is M3. The range of EQ-5D indices could be 1 to -0.171 with the worse health conditions indicated by smaller values [22].

There were five age groups: $40-49,50-59,60-69,70-79$, and $\geq 80$ years of age. Income levels were divided into lower, lower-middle, upper-middle, and upper classes based on their personal income quartile, and the residential area was divided into urban and rural areas. Marital status was divided into three cases: married and living with a spouse; married, but not living with a spouse due to divorce, separation, or death; and unmarried. Insurance type was divided into those who paid insurance premiums based on income and medical aid recipients who did not pay premiums due to low income rates. Smoking status, alcohol intake per week, and aerobic exercise were used as lifestyle factors, where smoking status was divided into currently smoking and nonsmoking groups. Alcohol intake per week was divided into four groups: no drinking, once a week, 2-3 times a week, and $\geq 4$ times a week. Aerobic exercise was divided into three groups: $\leq 2 /$ week, $3-4 /$ week, and $\geq 5$ /week. Body mass index was used to define those with body mass index $<18.5$ as underweight, between 18.5 and 25 as normal, and $\geq 25$ as obese. Comorbidities such as hypercholesterolemia, hypertension, obesity, and diabetes were also included in the analysis.

\section{Statistical Analysis}

The KNHANES data were extracted using a multistage stratified cluster sampling method, which is a complex sample design method to improve the representativeness of the sample and accuracy of estimation. Therefore, this study reflected weight, strata, and cluster variables for accurate data analyses, and all statistical analyses were performed using a complex sample data analysis method. Data sets with missing values were not omitted to avoid bias in the dispersion of the estimates (standard error).

The prevalence of osteoarthritis in the stroke group was estimated using frequency analysis. The chi-squared test and $t$ test were performed to compare the differences in characteristics between the stroke group with and without osteoarthritis.

To predict the effect of osteoarthritis and other related factors on the HRQoL of the stroke group, multiple regression analyses were performed in which osteoarthritis, age group, aerobic exercise, drinking, type of insurance, and education level, and the statistically significant variables in the univariate analysis were used as independent variables. All data analyses were performed using the Statistical Analysis System (SAS), version 9.4 (SAS Institute Inc., Cary, NC, USA), based on a significance level of $p<0.05$.

\section{Results}

\section{Participant characteristics}

Among the 23,269 individuals who participated in the 7th KNHANES from 2016 to 2018, 13,959 were $\geq 40$ years of age (stroke group $n=416$, non-stroke group $n=13,535)$. The demographic characteristics of the stroke group with and without osteoarthritis are shown in Table 1. In the stroke group, osteoarthritis was high in $72.8 \%$ of women, and the frequency increased as the age group increased to $70-79$ years. The comorbidities and lifestyle factors are shown in Table 2. There was no significant difference between the stroke group with osteoarthritis and the stroke group without osteoarthritis, except for obesity. Obesity was significantly higher in the stroke group with osteoarthritis at $49.5 \%$; it was $38.3 \%$ in the stroke group without osteoarthritis. 
Table 1

Characteristics of participants

\begin{tabular}{|c|c|c|c|c|}
\hline Valuables & $\begin{array}{l}\text { Non-Osteoarthritis } \\
(n=313)\end{array}$ & $\begin{array}{l}\text { Osteoarthritis } \\
(n=103)\end{array}$ & $p$ value & $n$ \\
\hline Sex & & & $<0.001^{\dagger}$ & 416 \\
\hline Male & $195(62.3 \%)$ & $28(27.2 \%)$ & & \\
\hline Female & $118(37.7 \%)$ & $75(72.8 \%)$ & & \\
\hline Age (years) & & & $0.006^{\dagger}$ & 416 \\
\hline $40-49$ & $19(6.1 \%)$ & $2(1.9 \%)$ & & \\
\hline $50-59$ & $57(18.2 \%)$ & $9(8.7 \%)$ & & \\
\hline $60-69$ & $86(27.5 \%)$ & $24(23.3 \%)$ & & \\
\hline $70-79$ & $101(32.3 \%)$ & $52(50.5 \%)$ & & \\
\hline $80+$ & $50(16.0 \%)$ & $16(15.5 \%)$ & & \\
\hline Marital status & & & $<0.001^{\dagger}$ & 416 \\
\hline Married, Spouse+ & $224(71.6 \%)$ & $58(56.3 \%)$ & & \\
\hline Married, no spouse & $76(24.3 \%)$ & $44(42.7 \%)$ & & \\
\hline Not married & $13(4.2 \%)$ & $1(1.0 \%)$ & & \\
\hline Residence & & & 0.71 & 416 \\
\hline Urban & $127(40.6 \%)$ & 39 (37.9\%) & & \\
\hline Rural & $186(59.4 \%)$ & $64(62.1 \%)$ & & \\
\hline Income & & & 0.82 & 413 \\
\hline Low & $106(34.1 \%)$ & $39(38.2 \%)$ & & \\
\hline Middle-Low & $82(26.4 \%)$ & $23(22.5 \%)$ & & \\
\hline Middle-High & $62(19.9 \%)$ & $19(18.6 \%)$ & & \\
\hline High & $61(19.6 \%)$ & $21(20.6 \%)$ & & \\
\hline Insurance type & & & $0.089^{*}$ & 409 \\
\hline National Health Insurance & $278(90.0 \%)$ & $83(83.0 \%)$ & & \\
\hline Medical Aid & $31(10.0 \%)$ & $17(17.0 \%)$ & & \\
\hline Education & & & $<0.001^{\dagger}$ & 411 \\
\hline$\leq$ elementary school & $138(44.5 \%)$ & $70(69.3 \%)$ & & \\
\hline$\leq$ Middle school & $62(20.0 \%)$ & 14 (13.9\%) & & \\
\hline$\leq$ High school & 75 (24.2\%) & $12(11.9 \%)$ & & \\
\hline$\geq$ University & $35(11.3 \%)$ & $5(5.0 \%)$ & & \\
\hline \multicolumn{5}{|l|}{${ }^{*} p<0.1$} \\
\hline${ }^{\dagger} p<0.01$ & & & & \\
\hline
\end{tabular}


Table 2

Comorbidities and lifestyle factors of participants

\begin{tabular}{|c|c|c|c|c|}
\hline Valuables & $\begin{array}{l}\text { Non-Osteoarthritis } \\
(n=313)\end{array}$ & $\begin{array}{l}\text { Osteoarthritis } \\
(n=103)\end{array}$ & $p$ value & $n$ \\
\hline Hypercholesterolemia & & & 0.178 & 365 \\
\hline No & $172(63.0 \%)$ & $50(54.3 \%)$ & & \\
\hline Yes & $101(37.0 \%)$ & $42(45.7 \%)$ & & \\
\hline Obesity & & & $0.077^{*}$ & 416 \\
\hline Low weight & $11(3.5 \%)$ & $1(1.0 \%)$ & & \\
\hline Normal & $182(58.1 \%)$ & $51(49.5 \%)$ & & \\
\hline Obesity & $120(38.3 \%)$ & $51(49.5 \%)$ & & \\
\hline Hypertension & & & 0.434 & 414 \\
\hline No & $91(29.2 \%)$ & $25(24.5 \%)$ & & \\
\hline Yes & $221(70.8 \%)$ & 77 (75.5\%) & & \\
\hline Diabetes & & & 0.21 & 365 \\
\hline No & $165(60.4 \%)$ & $63(68.5 \%)$ & & \\
\hline Yes & $108(39.6 \%)$ & $29(31.5 \%)$ & & \\
\hline Alcohol intake per week & & & $0.044^{\dagger}$ & 414 \\
\hline No drinking & $125(40.2 \%)$ & $54(52.4 \%)$ & & \\
\hline$\leq 1 /$ week & $107(34.4 \%)$ & $35(34.0 \%)$ & & \\
\hline 2-3/week & $40(12.9 \%)$ & $9(8.7 \%)$ & & \\
\hline$\geq 4$ /week & $39(12.5 \%)$ & $5(4.9 \%)$ & & \\
\hline Smoking status & & & $0.008^{\ddagger}$ & 413 \\
\hline No & 245 (79.0\%) & 94 (91.3\%) & & \\
\hline Yes & $65(21.0 \%)$ & $9(8.7 \%)$ & & \\
\hline Aerobic exercise & & & 0.318 & 409 \\
\hline$\leq 2 /$ week & $134(43.4 \%)$ & $52(52.0 \%)$ & & \\
\hline $3-4 /$ week & $53(17.2 \%)$ & $14(14.0 \%)$ & & \\
\hline$\geq 5 /$ week & 122 (39.5\%) & $34(34.0 \%)$ & & \\
\hline \multicolumn{5}{|l|}{${ }^{*} p<0.1$} \\
\hline \multicolumn{5}{|l|}{${ }^{\dagger} p<0.05$} \\
\hline${ }^{\ddagger} p<0.01$ & & & & \\
\hline
\end{tabular}

[Table 1 Characteristics of participants]

[Table 2 Comorbidities and lifestyle factors of participants]

\section{Prevalence of osteoarthritis in the stroke group}

The prevalence of osteoarthritis in the stroke and non-stroke groups was $21.72 \%$ and $12.49 \%$, respectively. With a chi-squared value of 25.1611 and a $p$ value of $<0.0001$, there was a statistically significant difference in the prevalence of osteoarthritis according to the presence or absence of stroke in individuals $\geq$ 40 years of age. The prevalence of osteoarthritis in female stroke patients $\geq 40$ years of age was $35.95 \%$, which was significantly higher than that in male patients $(10.23 \%)$. According to age, the prevalence of osteoarthritis was the highest in both men and women between the ages of $70-79$ years, being $18.38 \%$ and $46.94 \%$, respectively (Table 3 ). 
Table 3

Prevalence osteoarthritis in stroke group according to sex and age group

\begin{tabular}{|lllllll|}
\hline \multirow{2}{*}{ Age group } & \multicolumn{2}{l}{ Male } & \multicolumn{2}{l}{ Female } & \multicolumn{2}{l|}{ Total } \\
\cline { 2 - 7 } & $\boldsymbol{n}$ & Percent \pm SD & $\boldsymbol{n}$ & Percent \pm SD & $\boldsymbol{n}$ & Percent \pm SD \\
\hline $40-49$ & 0 & - & 2 & $17.17 \pm 13.87$ & 2 & $5.64 \pm 4.86$ \\
\hline $50-59$ & 0 & - & 9 & $24.23 \pm 8.26$ & 9 & $9.18 \pm 3.21$ \\
\hline $60-69$ & 10 & $13.75 \pm 4.91$ & 14 & $29.53 \pm 8.71$ & 24 & $20.13 \pm 4.72$ \\
$70-79$ & 14 & $18.38 \pm 5.51$ & 38 & $46.94 \pm 6.28$ & 52 & $32.76 \pm 4.16$ \\
\hline $80+$ & 4 & $11.12 \pm 5.59$ & 12 & $40.76 \pm 9.08$ & 16 & $28.04 \pm 5.95$ \\
\hline Total & 28 & $10.23 \pm 2.36$ & 75 & $35.95 \pm 3.99$ & 103 & $21.72 \pm 2.26$ \\
\hline SD, standard deviation. & & & & \\
\hline
\end{tabular}

\section{Differences in HRQoL according to the presence or absence of osteoarthritis in the stroke group}

This study used the EQ-5D index as an indicator of the HRQoL, and the averages for each item were compared [20]. When comparing all areas, the average score for each dimension was high in the stroke group with osteoarthritis, indicating a poor HRQoL. The EQ-5D index was lower in the stroke group with osteoarthritis (weighted mean \pm standard deviation [SD], $0.84 \pm 0.01$ ) than in those without osteoarthritis (weighted mean \pm SD, $0.73 \pm 0.02$ ). The $t$ test was performed to determine if the mean difference of each group was statistically significant, and there were significant differences in mobility, pain/discomfort dimensions, and EQ-5D index with $p<0.05$ (Table 4).

Table 4

Health-related quality of life by osteoarthritis in stroke group

\begin{tabular}{|llll|}
\hline Variables & $\begin{array}{l}\text { Non-Osteoarthritis } \\
(\boldsymbol{n = 3 1 3 )}\end{array}$ & $\begin{array}{l}\text { Osteoarthritis } \\
(\boldsymbol{n}=103)\end{array}$ & \multicolumn{1}{c|}{ t value } \\
\cline { 2 - 3 } & Mean (SD) & Mean (SD) & \\
\hline EQ-5D index score & $0.84(0.01)$ & $0.73(0.02)$ & $4.02^{*}$ \\
\hline Mobility & $1.48(0.05)$ & $1.77(0.07)$ & $-3.48^{*}$ \\
\hline Self-care & $1.30(0.05)$ & $1.35(0.06)$ & -0.64 \\
\hline Usual activities & $1.42(0.05)$ & $1.58(0.08)$ & -1.65 \\
\hline Pain/discomfort & $1.56(0.06)$ & $1.93(0.08)$ & $-3.63^{*}$ \\
\hline Anxiety/depression & $1.27(0.05)$ & $1.31(0.06)$ & -0.49 \\
\hline EQ-5D, European quality of life-5 dimension; SD, standard deviation. & \\
\hline${ }^{*} p<0.05$ & & & \\
\hline
\end{tabular}

\section{Factors affecting HRQoL in the stroke group $\geq \mathbf{4 0}$ years}

Multiple regression results for the EQ-5D index indicated that osteoarthritis, aerobic exercise, alcohol intake per week, type of insurance, and education level were significantly associated with $\mathrm{HRQ} O \mathrm{~L}$ in the stroke group $(\mathrm{F}=5.85, p<0.0001)$. Multiple regression models estimated to explore factors associations with EQ-5D index scores found that the presence of osteoarthritis and insurance type were significantly and negatively associated with EQ-5D index scores (both $p$ $<0.05$ ). The presence of osteoarthritis was associated with a reduction in EQ-5D index scores of approximately -0.145 ( $95 \%$ confidence interval [Cl]: -0.128 to $-0.020)$, and insurance type was associated with a reduction of approximately -0.140 ( $95 \% \mathrm{Cl}:-0.158$ to -0.023$)$, while aerobic exercise more than five times a week was associated with an increase in EQ-5D index score of approximately 0.187 (95\% Cl: 0.032 to 0.126 ), and drinking $\leq 1$ per week, $2-3$ per week, and $\geq 4$ per week were associated with an increase of approximately 0.116 (95\% Cl: 0.000 to 0.101$), 0.132$ (95\% Cl: 0.023 to 0.132 ), and 0.103 ( $95 \%$ Cl: 0.008 to $0.123)$, respectively. In addition, education above university level was associated with an increase in EQ-5D index score of approximately 0.121 ( $95 \% \mathrm{Cl}: 0.022$ to 0.133 ) (Table 5). 
Table 5

Factors influencing the health-related quality of life in stroke group

\begin{tabular}{|c|c|c|c|c|c|}
\hline \multirow[t]{2}{*}{ Variables } & \multicolumn{5}{|c|}{ multivariate } \\
\hline & B & SE & $\beta$ & $p$ value & $95 \% \mathrm{Cl}$ \\
\hline \multicolumn{6}{|l|}{ Osteoarthritis } \\
\hline No & reference & & & & \\
\hline Yes & -0.074 & 0.027 & -0.145 & 0.007 & -0.128 to -0.020 \\
\hline \multicolumn{6}{|l|}{ Age group } \\
\hline $40-49$ & reference & & & & \\
\hline $50-59$ & 0.015 & 0.041 & 0.029 & 0.719 & -0.065 to 0.094 \\
\hline $60-69$ & 0.023 & 0.041 & 0.050 & 0.569 & -0.057 to 0.104 \\
\hline $70-79$ & -0.021 & 0.044 & -0.047 & 0.633 & -0.107 to 0.065 \\
\hline $80+$ & -0.049 & 0.049 & -0.079 & 0.32 & -0.146 to 0.048 \\
\hline \multicolumn{6}{|l|}{ Aerobic exercise } \\
\hline$\leq 2 /$ week & reference & & & & \\
\hline $3-4 /$ week & 0.05 & 0.031 & 0.093 & 0.11 & -0.011 to 0.112 \\
\hline$\geq 5 /$ week & 0.079 & 0.024 & 0.187 & 0.001 & 0.032 to 0.126 \\
\hline \multicolumn{6}{|l|}{ Alcohol intake per week } \\
\hline No drinking & reference & & & & \\
\hline$\leq 1 /$ week & 0.051 & 0.026 & 0.116 & 0.048 & 0.000 to 0.101 \\
\hline 2-3/week & 0.077 & 0.028 & 0.132 & 0.006 & 0.023 to 0.132 \\
\hline$\geq 4 /$ week & 0.066 & 0.029 & 0.103 & 0.025 & 0.008 to 0.123 \\
\hline \multicolumn{6}{|l|}{ Insurance type } \\
\hline National Health Insurance & reference & & & & \\
\hline Medical Aid & -0.09 & 0.034 & -0.140 & 0.008 & -0.158 to -0.023 \\
\hline \multicolumn{6}{|l|}{ Education level } \\
\hline$\leq$ Elementary school & reference & & & & \\
\hline$\leq$ Middle school & -0.009 & 0.031 & -0.017 & 0.781 & -0.070 to 0.053 \\
\hline$\leq$ High school & 0.007 & 0.031 & 0.015 & 0.812 & -0.053 to 0.068 \\
\hline$\geq$ University & 0.077 & 0.028 & 0.121 & 0.006 & 0.022 to 0.133 \\
\hline
\end{tabular}

[Table 5 Factors influencing the health-related quality of life in stroke group]

\section{Discussion}

In this study, the prevalence of osteoarthritis in the stroke group was significantly higher than in the non-stroke group: $21.7 \%$ and $12.5 \%$, respectively. In the stroke group, the prevalence of osteoarthritis increased with age up to 70-79 years, and was higher in females. This finding suggests that stroke survivors, especially those of older age and females, are more vulnerable to osteoarthritis than the general population.

Given Korea's progression to a super-aged society, the significance of stroke and osteoarthritis in Korea is expected to grow in the future. Additionally, due to advances in medical technology, the improved quality of health care, and health promotion over the past several decades, the mortality rate of acute stroke has decreased, and the survival period has increased. Considering what we continued to look at in this study, the longer the period of suffering from stroke, the more likely the degree of osteoarthritis symptoms in the patient group will affect HRQoL.

Stroke is a disease that is highly associated with chronic or permanent disorders. In particular, osteoarthritis may be accelerated due to biomechanical problems such as paralysis, spasticity, sensory loss, movement disorders, and physical disorders [23, 24]. Knee osteoarthritis in patients with stroke was associated with an increase in the length of hospitalization and was found to be related to the degree of their daily activities [25]. Gait issues in patients with stroke showed a significant relationship with knee pain at rest, and knee osteoarthritis is known to be closely related to functional recovery after the onset of stroke $[26,27]$. Therefore, when proper evaluation and management including rehabilitation for patients with osteoarthritis are provided, it could improve their HRQoL. 
Second, the present study found that EQ-5D index scores in stroke patients with osteoarthritis were significantly higher in terms of mobility and pain/discomfort compared to the control group without osteoarthritis. The current findings indicated that hallmark symptoms (e.g., joint pain and gait difficulty) of osteoarthritis contribute to functional limitation and worsen HRQoL in the stroke group, suggesting that a preventive approach for stroke patients with osteoarthritis can improve their quality of life.

Lastly, HRQoL in the stroke group was affected by the presence of osteoarthritis, aerobic exercise, alcohol use, insurance type, and education level. Osteoarthritis and type of insurance (i.e., medical benefit) were associated with decreased HRQoL in the stroke group. That is, improving the medical benefit group's financial situation can contribute to a better quality of life. The other factors associated with a positive effect on HRQoL were aerobic exercise and alcohol intake per week. These findings are consistent with previous studies reporting that aerobic exercise improves HRQoL in stroke patients [28] and highlights the role of patient education on physical activity and exercise. Interestingly, although HRQoL was higher in the alcohol intake group than in the no drinking group, caution is needed when interpreting this result. Further studies should be considered to investigate the effect of drinking habits and types of alcohol on HRQoL in stroke patients.

This study has several limitations. First, this was a retrospective cross-sectional study that included a survey; it is difficult to identify the sequential or causal relationships of stroke patients and HRQoL. Second, although we conducted a secondary analysis of the KNHANES, the number of samples used in the final analysis was 416 , which is less than the total number of stroke patients in Korea. Third, the classifications and analyses according to detailed lesions, morbidity, or severity of osteoarthritis were not performed in detail. Future research is needed to analyze the relationship between the characteristics of osteoarthritis and HRQoL in stroke patients.

\section{Conclusion}

This study confirmed that the HRQoL, as assessed by the EQ-5D index, was significantly lower in patients with a co-occurrence of stroke and osteoarthritis. Therefore, in order to improve the quality of life of stroke patients and to further promote their happiness and social participation, the active management of osteoarthritis, including appropriate medical approaches such as preventive exercise, pain control, physical therapy, rehabilitation, and focused attention are necessary.

\section{Abbreviations}

HRQoL

Health-related quality of life; KNHANES:Korean national health and nutrition examination survey; EQ-5D:European quality of life-5 dimension; SD:standard deviation; Cl:confidence interval

\section{Declarations}

\section{Acknowledgements}

Not applicable

\section{Authors' contributions}

All authors had access to the data that was analyzed in the study. HJL contributed to the conception and design of the study, interpretation of data and performed the statistical analysis. All authors were responsible for writing the manuscript. All authors interpreted the findings and critically revised the manuscript. All authors approved the final version of the manuscript before submission.

\section{Funding}

No funding was received in support of this work.

\section{Availability of data and materials}

The datasets used and/or analysed during the current study are available from the corresponding author on reasonable request.

\section{Ethics approval and consent to participate}

This study was approved by the institutional review board of Jeju National University Hospital (IRB No.2020-05-001).

\section{Consent for publication}

Not applicable.

\section{Competing interests}

The authors declare that they have no competing interests.

\section{References}


1. Yoon H. Factors affecting quality of life of the Korean aged stroke patients. Int J Aging Hum Dev. 1997;44:167-81.

2. Lawrence L, Christie D. Quality of life after stroke: a three-year follow-up. Age Ageing. 1979;8:167-72.

3. King RB. Quality of life after stroke. Stroke. 1996;27:1467-72.

4. Kwon S, Park JH, Kim WS, Han K, Lee Y, Paik NJ. Health-related quality of life and related factors in stroke survivors: data from Korea National Health and Nutrition Examination Survey (KNHANES) 2008 to 2014. PLoS One. 2018;13:e0195713.

5. Kim JY, Kang K, Kang J, Koo J, Kim D-H, Kim BJ, et al. Executive summary of stroke statistics in Korea 2018: a report from the Epidemiology Research Council of the Korean Stroke Society. J Stroke. 2019;21:42.

6. Hong KS, Bang OY, Kang DW, Yu KH, Bae HJ, Lee JS, et al. Stroke statistics in Korea: part I. Epidemiology and risk factors: a report from the korean stroke society and clinical research center for stroke. J Stroke. 2013;15:2.

7. Gresham GE, Phillips T, Wolf P, McNamara P, Kannel W, Dawber T. Epidemiologic profile of long-term stroke disability: the Framingham study. Arch Phys Med Rehabil. 1979;60:487-91.

8. Adamson J, Beswick A, Ebrahim S. Is stroke the most common cause of disability? J Stroke Cerebrovasc Dis. 2004;13:171-7.

9. McLean DE. Medical complications experienced by a cohort of stroke survivors during inpatient, tertiary-level stroke rehabilitation. Arch Phys Med Rehabil. 2004;85:466-9.

10. Edgley SR, Gershkoff AM. Common pain syndromes in stroke patients: review of two cases. Top Stroke Rehabil. 2010;17:179-82.

11. Lee HS. Prevalence of osteoarthritis and related risk factors in the elderly: data from the Fifth Korean National Health and Nutrition Examination Survey 2010 2012. J Korean Diet Assoc. 2014;20:99-109.

12. Felson DT, Naimark A, Anderson J, Kazis L, Castelli W, Meenan RF. The prevalence of knee osteoarthritis in the elderly: the Framingham osteoarthritis study. Arthritis Rheum. 1987;30:914-8.

13. Dillon CF, Rasch EK, Gu Q, Hirsch R. Prevalence of knee osteoarthritis in the United States: arthritis data from the Third National Health and Nutrition Examination Survey 1991-94. J Rheumatol. 2006;33:2271-9.

14. Jung JH, Seok H, Kim JH, Song GG, Choi SJ. Association between osteoarthritis and mental health in a Korean population: a nationwide study. Int J Rheum Dis. 2018;21:611-9.

15. Kaufman KR, Hughes C, Morrey BF, Morrey M, An K-N. Gait characteristics of patients with knee osteoarthritis. J Biomech. 2001;34:907-15.

16. Valderrabano V, Nigg BM, von Tscharner V, Stefanyshyn DJ, Goepfert B, Hintermann B. Gait analysis in ankle osteoarthritis and total ankle replacement. Clin Biomech (Bristol Avon). 2007;22:894-904.

17. Felce D, Perry J. Quality of life: Its definition and measurement. Res Dev Disabil. 1995;16:51-74.

18. Min SJ. Aging vulnerability index of Korea. The Korean Journal of Economics. 2012;19:49-80.

19. Kontis V, Bennett JE, Mathers CD, Li G, Foreman K, Ezzati M. Future life expectancy in 35 industrialised countries: projections with a Bayesian model ensemble. Lancet. 2017;389:1323-35.

20. Rabin R, de Charro F. EQ-SD: a measure of health status from the EuroQol Group. Ann Med. 2001;33:337-43.

21. Nam HS, Kim KY, Kwon SS, Koh KW, Paul K. Research Report for estimated weight for Quality of Life Survey (EQ-5D). Cheongju: Korea Centers for Disease Control and Prevention; 2007.

22. Oh HS. Important significant factors of health-related quality of life(EQ-5D) by age group in Korea based on KNHANES(2014). Journal of the Korean Data Information Science Society. 2017;28:573-84.

23. Kendall R. Musculoskeletal problems in stroke survivors. Top Stroke Rehabil. 2010;17:173-8.

24. Kim GT, Jung ME. Musculoskeletal problems in lower extremity after stroke. Brain Neurorehabil. 2016;9:13-9.

25. Nguyen-Oghalai TU, Ottenbacher KJ, Granger CV, Goodwin JS. Impact of osteoarthritis on the rehabilitation of patients following a stroke. Arthritis Rheum. 2005;53:383-7.

26. Doruk P. The impact of knee osteoarthritis on rehabilitation outcomes in hemiparetic stroke patients. J Back Musculoskelet Rehabil. 2013;26:207-11.

27. Jeong H, Baek SY, Kim SW, Eun YH, Kim IY, Lee J, et al. Comorbidities and health-related quality of life in Koreans with knee osteoarthritis: data from the Korean National Health and Nutrition Examination Survey (KNHANES). PLoS One. 2017;12:e0186141.

28. Chen MD, Rimmer JH. Effects of exercise on quality of life in stroke survivors: a meta-analysis. Stroke. 2011;42:832-7.

\section{Figures}




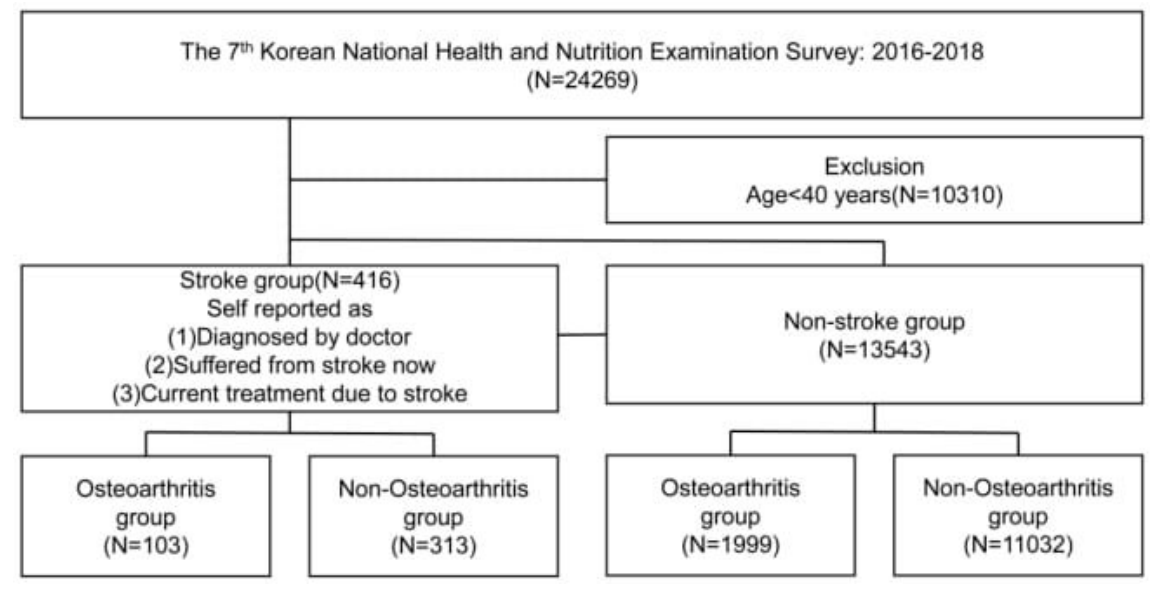

Figure 1

Flow chart of the study 